\title{
Predicting the Effect of Physical Parameters on the Amplitude of the Passive Cochlear Model
}

\section{Predecir el efecto de los parámetros físicos sobre la amplitud del modelo coclear pasivo}

\author{
F. Kouilily', F. E. Aboulkhouatem?', M. El khasmi², N. Yousfi1, N. Achtaich' \\ 'Department of Mathematics and Computer Science, Faculty of science Ben M'sik Hassan II University \\ 2Department of Biology, Faculty of science Ben M'sik Hassan II University
}

\begin{abstract}
The Cochlea plays a crucial role in the hearing of mammalian species including man. The basic function of the cochlea is to map sounds of different frequencies into corresponding characteristic positions on the basilar membrane. Many disciplines meet in the study of the auditory system to understand the truth function of the cochlea. An abnormality or small perturbation in the physical parameters of the cochlea may result a malfunction in the auditory system. In this paper, we developed a mathematical model in the order to show numerically the effect of stiffness and damping on the amplitude displacement in the case of a passive cochlea with the objective to study the ear dysfunction.
\end{abstract}

KEYWORDS: Passive, mathematial model, basilar membrane, damping, stiffness. 


\section{RESUMEN}

La cóclea desempeña un papel crucial en la audición de algunos mamíferos, incluyendo los seres humanos. Su función básica es la de un mapa de los sonidos de diferentes frecuencias a las posiciones características correspondientes en la membrana basilar. Muchas disciplinas se encuentran en el estudio del sistema 26 auditivo para comprender la función de la verdad de la cóclea. Una anormalidad o una pequeña perturbación en la característica física de la cóclea puede producir un mal funcionamiento en el sistema auditivo. En este trabajo, se desarrolló un modelo matemático en el orden de mostrar numéricamente el efecto de rigidez y amortiguación sobre el desplazamiento de amplitud en el caso de una cóclea pasiva con el objetivo de estudiar la disfunción del oído.

PALABras CLAVE: Pasiva, modelo matemático, membrana basilar, amortiguación, rigidez.

\section{Correspondencia}

DESTINATARIO: Fatiha Kouilily

INSTITUCIÓN: Department of Mathematics and

Computer Science, Faculty of science Ben M'sik

Hassan II University

DIRECCIÓN: P. O. Box 7955, Sidi Othman, Casablanca,

Morocco

CORREOELECTRÓNICO: kouililyfatiha@gmail.com

\section{Fecha de recepción:}

8 de octubre de 2017

Fecha de aceptación:

15 de diciembre de 2017 


\section{INTRODUCTION}

The cochlea is the primary receptor organ for hearing, its principal role is to transform incoming sound pressure into vibrations of the basilar membrane which give rise to electrical signals ${ }^{[1]}$, it has been an object of research for several decades. The human cochlea has a spiral form with two and a half turns and consists of three fluid filled compartments: scala vestibuli, scala media, and scala tympani from the basal turn to apex (show Figure 1). The scala vestibuli and scala tympani are separated by the cochlear partition which consists of the Basilar Membrane (BM) and the organ of Corti ${ }^{[2][3]}$.
Mammalian auditory systems have the capability of detecting and analyzing sounds over a wide range of frequency and intensity, for example, humans can hear sounds with frequencies from $20 \mathrm{~Hz}$ to $20 \mathrm{kHz}$ and over an intensity range up to 120 decibels ${ }^{[4]}$.

Generally, cochlear hearing loss involves damage in the structure inside the cochlea, and can be observed in the response of the BM. Abnormalities in the BM's function can result in many diseases that can be lead to the hearing loss. An example of such a diseases is the Alport Syndrome (AS) ${ }^{[5]}$ and Meniere's disease. As it is already known that the cochlea is inaccessible

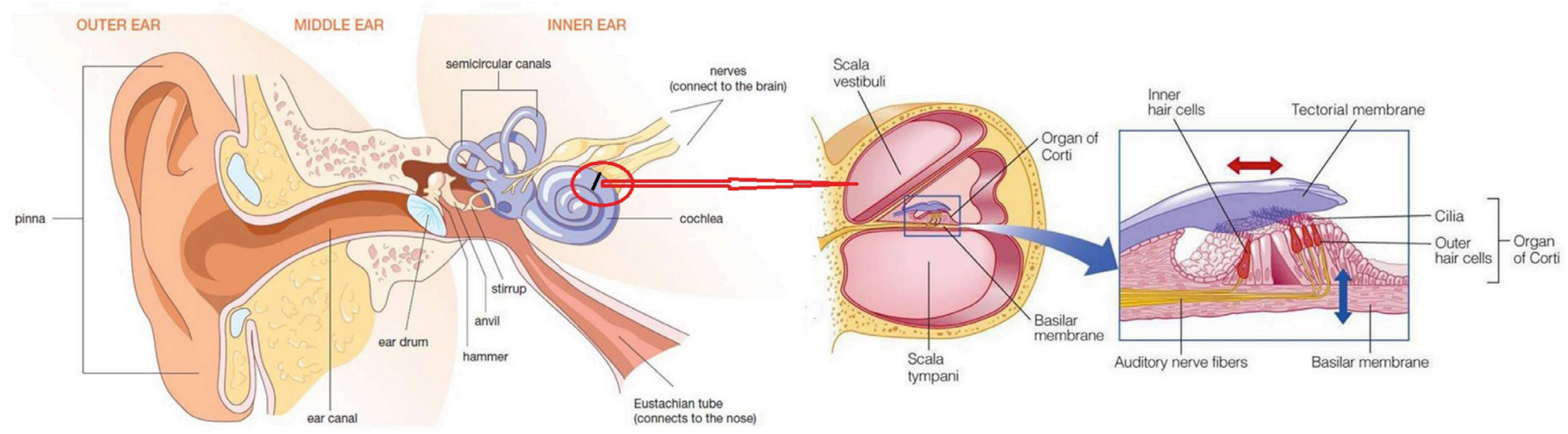

FIGURE 1. The structure of the cochlea.

during life, which means that the pathologic basis of hearing loss can only be obtained by post-mortem studies of the cochlea or by developing credible animal models. Mathematical modeling is therefore, particularly attractive tool in cochlea's research and its pathology ${ }^{[6]}$. The majority of human cochlea modeling focuses on efforts to accurately simulate BM vibratory characteristics ${ }^{[7]}$ by using system of forced harmonic oscillators equation that has been previously proposed by Lesser and Berkeley ${ }^{[8]}$ and developed by JimenezHernandez ${ }^{[9]}$ with the objective to obtain a relation for determining the effect of physical parameters of BM on its maximum amplitude displacement in response to an input stimulus in the auditory system.
To contribute to the knowledge of alterations associated to cochlear disorders in BM, this paper aims to explore and understand the decrease of the maximum amplitude displacement along the BM perturbation by using the computational passive cochlear model ${ }^{[9]}$. Based on the Jimenez-Hernandez model, we introduce new physicals parameters that we called $\varepsilon_{\mathrm{s}}$ and $\varepsilon_{\mathrm{d}}$ as a perturbation of stiffness and damping in the modeling equation of the BM displacement, with the objective to simulate the normal and abnormal function of the BM and predict the effect of increasing of the physicals parameters on the BM motion, so this model can be as an example of the utility of mathematical models to better understand the behavior of the inner ear. 


\section{MODEL OF THE PASSIVE COCHLEA}

In the modeling of the cochlea, there are two types: passive and active models. In passive cochlea, the vibration of one radial section of the cochlear partition (CP) is often simplified to BM movement only. However, in active cochlea, the vibrations of the different parts of the CP in relation to each other are modeled, as well as the detailed motions of the cellular structures within the Organ of Corti (OC), in our work, we used the passive model.

The cochlea is modeled as having two rectangular compartments filled with fluid and separated by the $\mathrm{BM}$, as adopted from the model of Lesser and Berkley ${ }^{[8]}$. The upper compartment corresponds to the scala vestibuli, and the lower compartment to the scala tympani. For simplicity, the scala media is omitted from the model ${ }^{[10]}$ as shown in Figure 2.

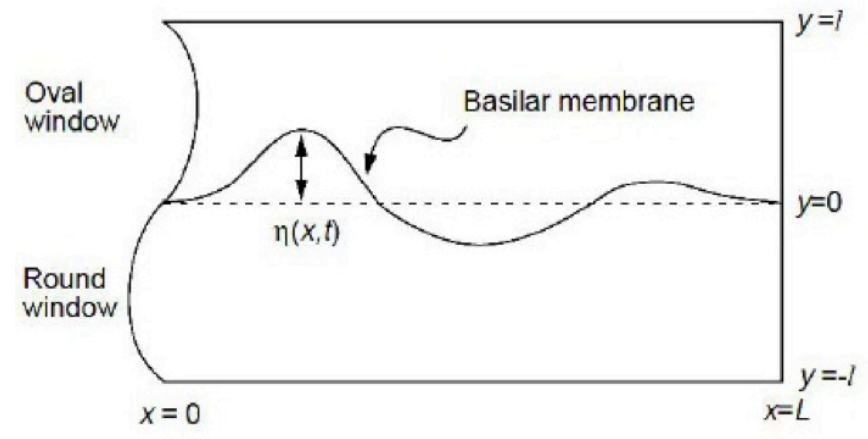

FIGURE 2. Shematic diagram of the cochlea, adapted

from the model of Lesser and Berkley (1972).

The whole BM can be modeled as a harmonic oscilla-tor having varying properties along the membrane such as $\mathrm{m}(\mathrm{x})$ mass per unit area, $\mathrm{C}(\mathrm{x})$ damping coeffi-cient, and $\mathrm{k}(\mathrm{x})$ stiffness per unit area ${ }^{[9]}$. The deflection of the membrane is then represented by a one-dimensional wave equation $\eta$ which is the solution to the forced harmonic oscillator equation;

$$
m(x) \frac{\partial^{2} \eta}{\partial t^{2}}+C(x) \frac{\partial \eta}{\partial t}+k(x) \eta=F e^{j \omega t}
$$

We consider each section of the Membrane as a forced harmonic oscillator, which is excited by an external force $\mathrm{Fe}^{\mathrm{j} \omega t}$ that represents the driving force on each section of the BM. This force is produced by vibration transmitted into the cochlea by the oval window, where $\mathrm{F}$ is the magnitude of the driving force and $\omega$ is its angular frequency. This implies that the driving force $F e^{j \omega t}$ is periodic and complex. Therefore, we can consider that the displacement is also complex, and conclude that the solution of the differential equation is defined by displacement $\eta=A_{m} e^{j \omega t}$, where $A_{m}$ is the complex amplitude.

Our goal is to increase the stiffness $\mathrm{k}(\mathrm{x})$ and the damping $\mathrm{C}(\mathrm{x})$ in order to show the effect of this per-turbation on the amplitude $A_{m}$ of the displacement $\eta$, if we put $\mathrm{k}(\mathrm{x}) \leftarrow \mathrm{k}(\mathrm{x})+\varepsilon_{\mathrm{s}}$ and $\mathrm{C}(\mathrm{x}) \leftarrow \mathrm{C}(\mathrm{x})+\varepsilon_{\mathrm{d}}$, the differ-ential equation describing the resulting motion of the system is as follows

$$
\begin{gathered}
m(x) \frac{\partial^{2} \eta}{\partial t^{2}}+\left(C(x)+\varepsilon_{d}\right) \frac{\partial \eta}{\partial t}+\left(k(x)+\varepsilon_{s}\right) \eta=F \cos \omega t \\
\frac{\partial^{2} \eta}{\partial t^{2}}+2 \alpha \frac{\partial \eta}{\partial t}+\omega_{0}^{2} \eta=\frac{F}{m(x)} \cos \omega t
\end{gathered}
$$

Where

$$
2 \alpha=\frac{c(x)+\varepsilon_{d}}{m(x)}
$$

and

$$
\omega_{0}^{2}=\frac{k(x)+\varepsilon_{s}}{m(x)}
$$

The solution of the Equation (3) is defined as follow

$$
\eta=\eta^{(h)}+\eta^{(p)} \simeq \eta^{(p)}
$$

where

$$
\eta^{(p)}=A_{m} \cos (\omega t+\varphi)
$$


Using the complex form of $\eta$

$$
\underline{\eta}=A_{m} e^{j(\omega t+\varphi)}=\underline{A_{m}} e^{j \omega t}
$$

where

$$
\underline{A_{m}}=A_{m} e^{j \varphi}
$$

Then $\underline{\eta}$ is the solution of the following equation

$$
\frac{\partial^{2} \underline{\underline{\eta}}}{\partial t^{2}}+2 \alpha \frac{\partial \underline{\eta}}{\partial t}+\omega_{0}^{2} \underline{\underline{\eta}}=\frac{F}{m(x)} e^{j \omega t}
$$

Thus,

$$
\begin{aligned}
& \left(-\omega^{2}+2 \alpha j \omega+\omega_{0}^{2}\right) \underline{A_{m}}=\frac{F}{m(x)} \\
& \underline{A_{m}}=\frac{F}{m(x)\left(\left(\omega_{0}^{2}-\omega^{2}\right)+j 2 \alpha \omega\right)}
\end{aligned}
$$

Then the amplitude $A_{m}$ is defined by,

$$
A_{m}=\frac{F}{m(x) \sqrt{\left(\omega_{0}^{2}-\omega^{2}\right)^{2}+4 \alpha^{2} \omega^{2}}}
$$

Thus,

$$
A_{m}=\frac{F}{m(x) \sqrt{\left(\frac{k(x)+\varepsilon_{s}}{m(x)}-\omega^{2}\right)^{2}+\left(\frac{c(x)+\varepsilon_{d}}{m(x)}\right)^{2} \omega^{2}}}
$$

\section{NUMERICAL RESULTS}

Consider that the angular frequency is $\omega=2 \pi f$, the amplitude $A_{m}$ in Equation (8) can be expressed by,

$$
A_{m}=\frac{F}{m(x) \sqrt{\left(\frac{k(x)+\varepsilon_{s}}{m(x)}-4 \pi^{2} \mathrm{f}^{2}\right)^{2}+4 \pi^{2} \mathrm{f}^{2}\left(\frac{C(x)+\varepsilon_{d}}{m(x)}\right)^{2}}}
$$

Now, we can obtain the expression of the amplitude $A_{m}$ of displacement of the BM to a specific excitation frequency of the system occurs. For the values of $\mathrm{m}(\mathrm{x})$, $\mathrm{C}(\mathrm{x})$ and $\mathrm{k}(\mathrm{x})$, we use the parameters of Neely ${ }^{[11][12]}$.
In this section, we simulate our results to determine the effect of increasing the physical parameters on the amplitude $A_{m}$ of the displacement of basilar membrane.

Table 1 represents the values of $\mathrm{m}(\mathrm{x}), \mathrm{C}(\mathrm{x})$ and $\mathrm{k}(\mathrm{x})$ proposed by Neely ${ }^{[11]}$.

TABLE 1. Neely parameters

of passive cochlea model ${ }^{[1]}$.

\begin{tabular}{|l|c|c|c|}
\hline \multicolumn{1}{|c|}{ Parameter } & Symbol & Value & Unit \\
\hline Mass & $\mathrm{m}(\mathrm{x})$ & 0.15 & $\mathrm{~g} / \mathrm{cm}^{2}$ \\
\hline Damping & $\mathrm{C}(\mathrm{x})$ & 200 & dyn.s/ $\mathrm{cm}^{3}$ \\
\hline Stiffness & $\mathrm{k}(\mathrm{x})$ & $10^{9} e^{-2 x}$ & dyn $/ \mathrm{cm}^{3}$ \\
\hline
\end{tabular}

First, we studied the effect of an increase in the stiff-nesson amplitude $A_{m}$.

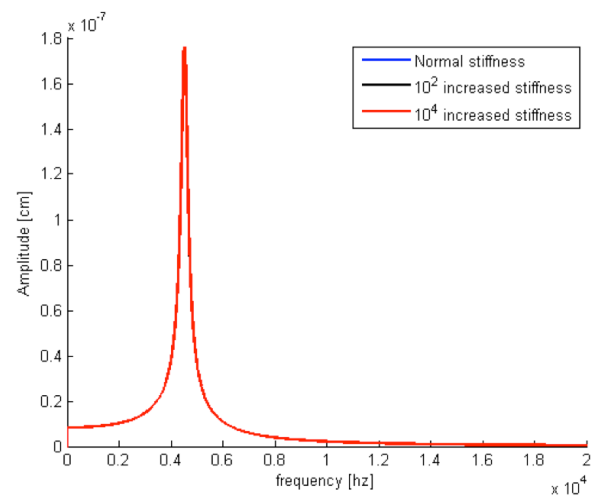

a)

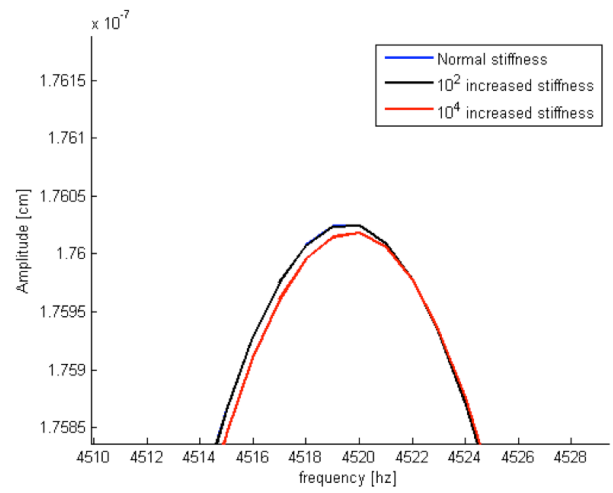

b)

FIGURE 3. (a) The changes observed in basilar membrane amplitude after an increase in the value of stiffness, (b) Zooming of (a). 
In the Figure 3, we show the results obtained by increasing the stiffness of BM. At the position of BM $\mathrm{x}=$ $1.05560 \mathrm{~cm}$, increasing the stiffness up to $102 \mathrm{normal}$, we observe that no slightly change in the amplitude of $\mathrm{BM}$, and when we increase the stiffness up to 104 normal caused larger decrease in the amplitude of BM.

To understand well, we plot the variation of the amplitude in function of the stiffness, this is illustrated in Figure 4.

a)
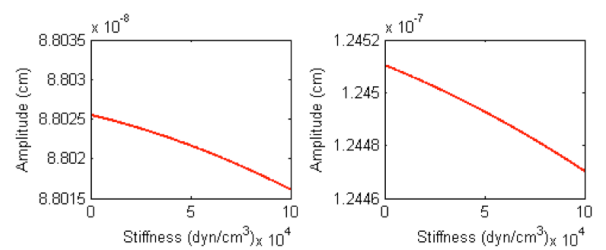

c)
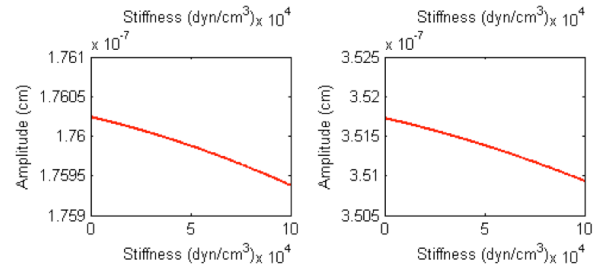

FIGURE 4. The amplitude of the BM displacement according to the perturbation stiffness. (a) $x=0.36281 \mathrm{~cm}$ and $\mathrm{f}=$ $9040 \mathrm{~Hz}$, (b) $x=0.7095 \mathrm{~cm}$ and $\mathrm{f}=6390 \mathrm{~Hz}$, (c) $x=1.05560$ $\mathrm{cm}$ and $\mathrm{f}=4520 \mathrm{~Hz},(d) \mathrm{x}=1.74700 \mathrm{~cm}$ and $\mathrm{f}=2260 \mathrm{~Hz}$.

In Figure 4, the amplitude decreases when the stiffness $\varepsilon_{s}$ increases, for example we take $0<\varepsilon_{s} \leq 10^{4}$. That means the BM becomes stiffer, which implies the hearing loss.

Next, we studied the effect of an increase in the damp-ing of BM on the Amplitude $A_{m}$. At the same position of $\mathrm{BM} \mathrm{x}=1.05560 \mathrm{~cm}$, increasing the damping up to $10^{2}$ normal substantially decreased the amplitude of BM.

Then, we plot the variation of the amplitude in function of the damping; this is illustrated in Figure 6.

The figure 6 confirms that the amplitude decreases, when we increase the perturbation damping $\varepsilon_{\mathrm{d}}$ along

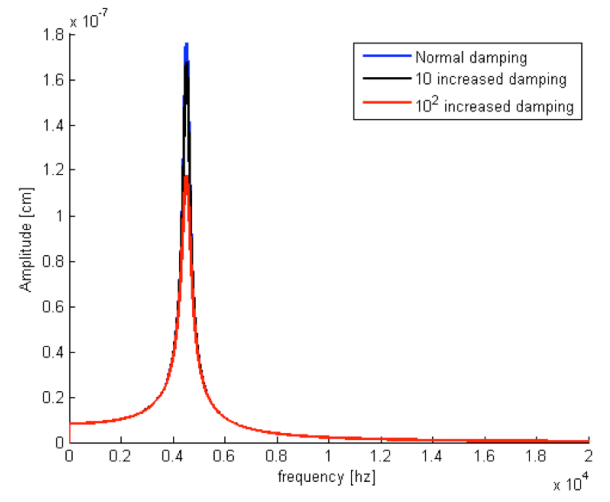

a)

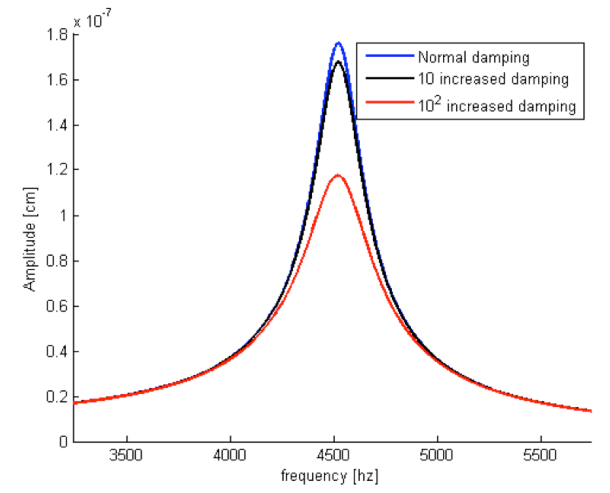

b)

FIGURE 5. (a) The changes observed in basilar

membrane amplitude after an increase in the value of damping, (b) Zooming of (a).

the length of the BM and various excitation frequen-cies. The maximum displacement of each distance decreases when the perturbation $\varepsilon_{\mathrm{d}}$ is above than 0.1 dyn.s/ $\mathrm{cm}^{3}$. a)
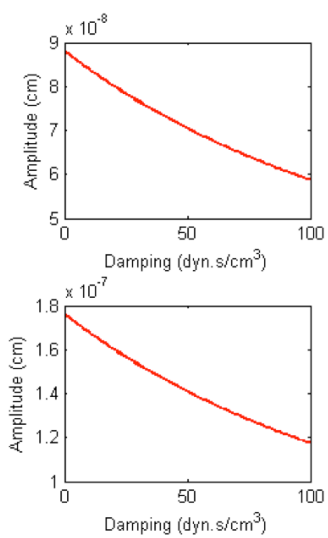
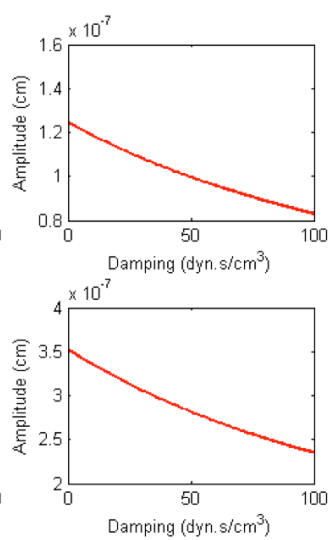

b)

d)
FIGURE 6. The amplitude of the BM displacement according to the perturbation damping. (a) $x=0.36281 \mathrm{~cm}$ and $\mathrm{f}=$ $9040 \mathrm{~Hz}$, (b) $x=0.7095 \mathrm{~cm}$ and $\mathrm{f}=6390 \mathrm{~Hz}$, (c) $x=1.05560$ $\mathrm{cm}$ and $\mathrm{f}=4520 \mathrm{~Hz}$, (d) $\mathrm{x}=1.74700 \mathrm{~cm}$ and $\mathrm{f}=2260 \mathrm{~Hz}$. 
Finally, in the Figure 7 we analyze the case when we increase the both parameters stiffness and damping, we observe that the increasing of stiffness and damping reduced the amplitude of $\mathrm{BM}$, which gives the per-turbation of functioning of the cochlea that load to hearing loss.

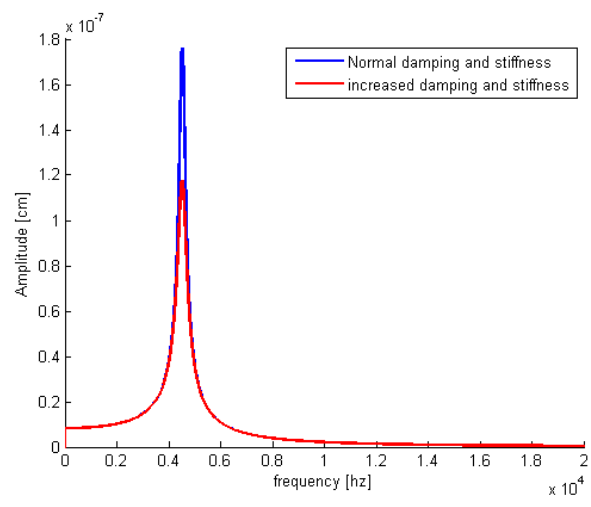

FIGURE 7. The changes observed in the basilar membrane amplitude after an increase in the value of stiffness and damping.

\section{CONCLUSIONS}

The cochlea is a very small and delicate organ and is very difficult to study experimentally. Many important questions of cochlea mechanics are mathemati-cally solved by using numerical simulations.
The present study investigated the predicting effect of physical parameters on the amplitude of BM. For this a passive cochlea model was developed using the solution of one dimensional equation.

Typical, an increase in stiffness or in damping system will change the forced response of a vibrating system, which is presented and verified in our studies by increasing the stiffness, damping and the both parameters.

By analysis the model, we have proved that the increasing of stiffness and damp ing reduced the amplitude of BM, which gives the per turbation of function-ing of the cochlea that can load to hearing loss. 


\section{REFERENCES}

[1] Russo M, Rozic N, Stella M. "Biophysical cochlear model: Timefrequency analysis and signal reconstruction," Acta Acust. United Acust., 2011; 97(4): 632-640.

[2] Gan RZ, Reeves BP, Wang X. "Modeling of sound transmission from ear canal to cochlea," Ann. Biomed. Eng., 2007; 35(12): 2180-2195.

[3] Pickles JO. "An Introduction to the Physiology of Hearing," UK: Emerald Group Publishing, 2012.

[4] Ni G, Elliott SJ, Ayat M, Teal PD. "Modelling Cochlear Mechanics," Biomed. Res. Int.,2014; 1-42.

[5] Aboulkhouatem FZ, Kouilily F et al.“The Active Model: The Effect of Stiffness on the Maximum Amplitude Displacement of the Basilar Membrane”. Brit.J. Math. \& Computer Sci. 20(6): 1-11, 2017, Article no BJMCS.30856 ISSN: 2231-0851.

[6] Merchant SN, McKenna MJ, Adams JC, Nadol JrJB, Fayad J, Gellibolian R et al. "Human Temporal Bone Consortium for Research Resource Enhancement," J. Assoc. Res. Otolaryngol., 2008; 9(1): 14 .
[7] Bhnke F, Arnold W. "3D-finite element model of the human cochlea including fluid-structure couplings," ORL J. Otorhinolaryngol. Relat. Spec., 1999; 61(5):305-310.

[8] Lesser MB, Berkeley DA. "Fluid Mechanics of the cochlea,". Part 1, J. Fluid Mech., 1972; 51: 497-51.

[9] Jimenez-Hernandez M, Oropeza-Rodríguez JL, Suarez Guerra S, Barrn-Fernndez R. "Computational Model of the Cochlea using Resonance Analysis," J. Rev. Mex. Ing. Biomed., 2012; 33(2):77-86.

[10] Keener J, Sneyd J. "Mathematical Physiology", Springer (USA), 2008; 8(1): 943-969.

[11] Neely ST. "Finite difference solution of a two-dimensional mathe-matical model of the cochlea," J. Acoust. Soc. Am., 1981; 69(5):1386-1391.

[12] Neely ST. "Mathematical modeling of cochlear mechanics," J. Acoust. Soc. Am., 1985; 78(1): 345-352 